\title{
Cell growth on microcarriers: comparison of proliferation on and recovery from various substrates*
}

\author{
James Varani, $\dagger+$ Matthew J. Bendelow, $\uparrow$ \\ John H. Chun§ and William A. Hillegas
}

\begin{abstract}
Three commercially-important types of cell were grown on four different microcarrier substrates. The cells, which included normal human diploid fibroblasts (MRC-5), primary chick embryo cells and Madin-Darby bovine kidney cells (MDBK), were compared with regard to proliferation on the substrates and with regard to recovery of viable cells from the same substrates. The substrates used included glass-coated microcarriers (Biosil), collagen microcarriers (Ventregel), DEAE-dextran microcarriers (Cytodex I) and collagen-linked DEAE-dextran microcarriers (Cytodex III). The established cell line (MDBK) grew well on all of the substrates and a high percentage of viable cells could be harvesced from each substrate. The MRC-5 cells also grew well on all four substrates but high recovery rates were achieved only with cells grown on the glass-coated microcarriers or collagen microcarriers. In contrast, the primary chick embryo cells grew well only on the glass microcarriers and the recovery rate of cells harvested from this substrate was high. In some industrial operations, the re-utilization of cells after removal from the substrate is necessary. In these situations the appropriate choice of microcarriers for the cultivation of the cells may be critical.
\end{abstract}

\section{INTRODUCTION}

Microcarriers (i.e. small spheres kept in suspension by gentle stirring) have been used as the substrate for the growth of anchorage-dependent animal cells since their introduc-

* Received for publication 3 March 1986

† The Department of Pathology, The University of Michigan Medical School, Ann Arbor, Michigan 48109 , USA.

‡ To whom correspondence should be addressed.

$\S$ The Division of Viral Vaccines, Connaught Laboratories, Ltd., Willowdale M2R 3T4, Ontario, Canada.

|| SoloHill Engineering, Inc., Ann Arbor, Michigan 48109 USA. 
tion in $1967 .{ }^{1}$ Among the materials which have been successfully used as microcarriers are DEAE-dextran, collagen-linked DEAE-dextran, polystyrene plastic, porous silica, polyacrylamide, collagen, liquid fluorocarbons and glass. ${ }^{1-5}$ Although each of these materials is capable of supporting cell growth, significant differences in growth and biological properties may be seen on the different substrates. In recent studies we compared the growth of human diploid fibroblasts on microcarriers made from DEAE-dextran and microcarriers made from glass. The cells grew to a higher density on the glass microcarriers and were more sensitive to trypsin-mediated release from the glass microcarrier surface than from DEAE-dextran microcarriers. There were also morphological and biochemical differences between the cells on the two substrates. 5,6 These observations were extended in reported study here. In this study, we examined the growth of three commercially important types of cell on several different microcarrier substrates and compared cell yields from each substrate with the plating efficiencies of the cells harvested from the same substrate. Significant substrate-dependent differences in growth and replating capacity were observed. In some industrial operations re-use of cells after removal from the substrate is part of the procedure. In these situations the appropriate choice of microcarriers for the cultivation of the cells may be critical.

\section{MATERIALS AND METHODS}

\section{Cells}

The cells used in these experiments included MRC-5 human diploid fibroblasts, primary chick embryo cells and Madin-Darby bovine kidney (MDBK) cells. Each of these cell types is an important substrate for the production of viral vaccines for human or veterinary use. The MRC-5 human fibroblasts were obtained from Flow Laboratories (McLean, Va), maintained in monolayer culture and used through passage 35. The chick embryo cells were prepared from ten-day-old fertilized hens eggs and used in primary culture. The MDBK cells were kindly provided by David Buell (Grand Laboratories; Larchwood, IO). All of the cells were maintained on minimal essential medium of Eagle with Earle's salts (MEM) supplemented with $10 \%$ fetal bovine serum, $100 \mathrm{U} / \mathrm{ml}$ penicillin, $100 \mu \mathrm{g} / \mathrm{ml}$ streptomycin and $0.25 \mu \mathrm{g} / \mathrm{ml}$ fungizone. Growth was at $37^{\circ} \mathrm{C}$ and $5 \% \mathrm{CO}_{2}$. Prior to use, and during the course of these studies, the MRC-5 and MDBK cells were examined for mycoplasma contamination by growth in mycoplasma broth and on mycoplasma agar. They were always shown to be free of contamination by these criteria.

\section{Microcarriers}

Four different, commercially-available microcarriers were used in these studies. These included microcariers made from DEAE-Dextran (Cytodex I) and collagenlinked DEAE-Dextran (Cytodex III), obtained from Pharmacia (Piscataway, NJ); collagen microcarriers (Ventregel), obtained from Ventrex Laboratories, Inc. (Portland, ME) and glass-coated microcarriers (Biosil), obtained from SoloHill Engineering (Ann Arbor, MI). Each of the four types of microcarrier was prepared for use according to the recommendations of the respective manufacturers.

\section{Microcarrier cultures}

The experiments were carried out in $200 \mathrm{ml}$ suspension microcarrier cultures as described in a recent report. 5 The amount of each microcarrier used was chosen to 
provide comparable surface areas. For Cytodex I, Cytodex III and Ventregel this was $1 \mathrm{~g} /$ culture. For the Biosil beads it was $5 \mathrm{~g} /$ culture. The cultures were established on day zero and cell growth determined on subsequent days. Total cells were enumerated using a nuclei assay. ${ }^{7}$ In parallel, cells were counted after removal from the microcarrier surface by trypsinization and replated in plastic flasks using the same growth medium. Four hours later the number of cells which had attached to the culture flask and spread was determined. Attachment was assessed by harvesting the cells with trypsin and counting them using a hemocytometer. Cell spreading was determined by removing the nonattached cells and then counting the total number of cells remaining and number of spread cells using an inverted microscope with a calibrated grid in the eyepiece.

\section{Adbesiveness}

Adhesiveness was assessed as the sensitivity of the cells to protease-mediated release from the substrate. For this, 2-ml samples of cells were harvested, separated from the growth medium and washed in serum-free culture medium. The samples were then treated with $2 \mathrm{ml}$ of $0.25 \%$ trypsin solution (Difco 1:250; Difco Laboratories, Detroit, MI) and incubated at $37^{\circ} \mathrm{C}$. At various times later the trypsin solution was gently aspirated and the detached cells counted using a hemocytometer. This assay procedure was the same as that used by us previously. ${ }^{8}$

\section{RESULTS}

\section{Cell growth}

Growth of the three cell types on the various microcarrier substrates is shown in Fig. 1. Total cell numbers were determined using nuclei preparations. It can be seen that
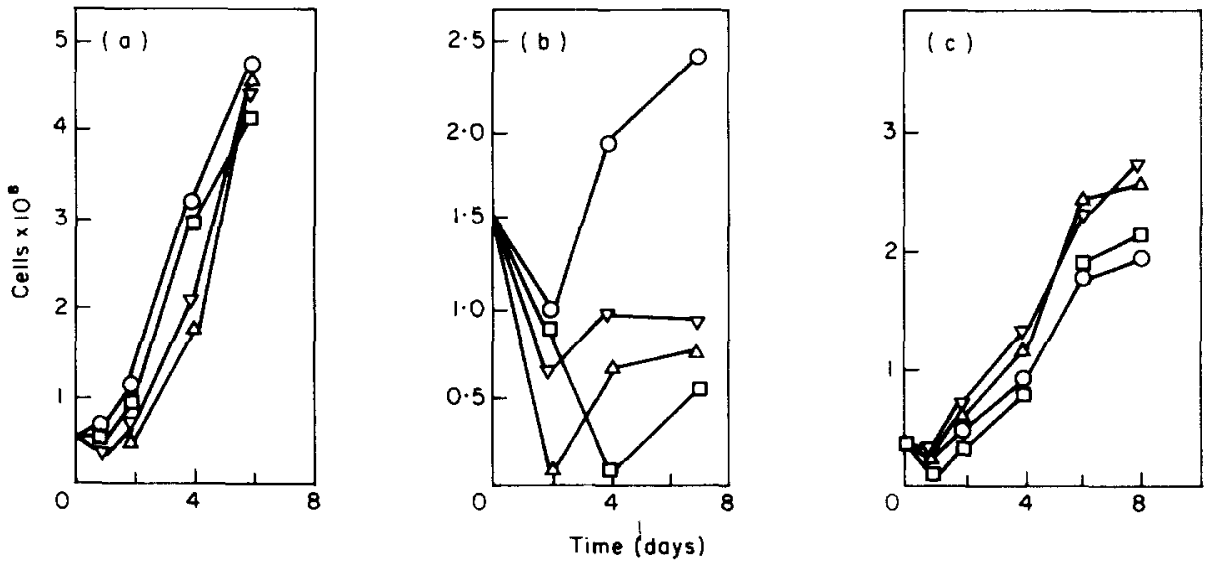

Fig. 1. Cell growth on various microcarriers. Microcarriers cultures were established on day zero as described in the Methods section. On each of the indicated days, 5-ml samples were obtained from each culture and the total number of cells determined using the nuclei assay. The values shown are averages of duplicate samples in a single expcriment. Each cell type was examincd five to seven times with similar results: (a) MDBK, (b) chick embryo, (c) MRC-5. O, Glass; $\square$, collagen; $\triangle$, DEAE-dextran; $\nabla$. collagen-linked DEAE-dextran. 
the two cell types maintained in culture (MRC-5 and MDBK) grew well on all of the substrates but that the primary chick cells grew to high density only on the glass microcarriers. Table 1 shows the plating efficiencies of the cells after harvesting with trypsin from the various microcarriers. Significant substrate-dependent differences were observed with the human fibroblasts and chick cells. The plating efficiency of the human (MRC-5) cells was much higher when they were harvested from the glass microcarriers or collagen microcarriers than when they were recultured from the DEAE-dextran or collagen-linked DEAE-dextran beads. High plating efficiency was observed only with the chick cells harvested from the glass microcarriers. In contrast, the MDBK cells harvested from all four microcarrier substrates reattached and spread when recultured.

TABLE 1. Plating efficiency of cells harvested from different microcarriers*

Percentage of the cells which reattached after harvesting from: $\dagger$

\begin{tabular}{lcccc}
\hline & \multicolumn{3}{c}{$\begin{array}{c}\text { Percentage of the cells which } \\
\text { reattached after harvesting from: } \dagger\end{array}$} \\
Cell type & Glass & Collagen & DEAE-dextran & $\begin{array}{c}\text { Collagen-linked } \\
\text { DEAE-dextran }\end{array}$ \\
\hline MDBK & & & & \\
Day 2 $\$$ & $85 \pm 6$ & $92 \pm 7$ & $91 \pm 8$ & $90 \pm 10$ \\
Day 4 & $92 \pm 7$ & $90 \pm 5$ & $75 \pm 10$ & $90 \pm 8$ \\
Day 6 & $82 \pm 3$ & $91 \pm 5$ & $83 \pm 10$ & $85 \pm 5$ \\
Chick embryo & $90 \pm 6$ & $74 \pm 9$ & $35 \pm 10$ & $74 \pm 6$ \\
Day 2 & $83 \pm 8$ & $22 \pm 5$ & $25 \pm 3$ & $64 \pm 5$ \\
Day 4 & $94 \pm 7$ & $5 \pm 5$ & $<5$ & $10 \pm 5$ \\
Day 6 & $68 \pm 10$ & $83 \pm 7$ & $25 \pm 8$ & $35 \pm 7$ \\
MRC-5 & $91 \pm 6$ & $101 \pm 15$ & $10 \pm 5$ & $15 \pm 8$ \\
Day 2 & & & \\
Day 4 & & & & \\
\hline
\end{tabular}

* The cells were grown on the microcarriers for $2-6$ days and then harvested with trypsin and replated in plastic flasks as described in the Methods section. After four hours the cells were harvested from the plastic flasks and counted. The number of harvested cells was then compared to the total cell count from the original microcarrier cultures (based on the nuclei assay) to provide a percentage value.

$\dagger$ The values are averages \pm the range based on two samples in a single experiment. Each cell line was examined in five to seven experiments with similar results.

$\ddagger$ This refers to the length of the incubation period on the microcarricrs prior to harvesting and replating.

\section{Adhesiveness}

The sensitivity of the cells on the various microcarriers to trypsin-mediated release from the substrate was measured (Fig. 2). Both cell-specific differences and substratespecific differences were noted. With the MRC-5 cells, the cells were readily released from the glass and collagen microcarriers but were extremely trypsin-resistant when grown on DEAE-dextran or on the collagen-linked DEAE-dextran microcarriers. In contrast, the chick embryo cells and MDBK cells were readily released from all of the substrates examined. 

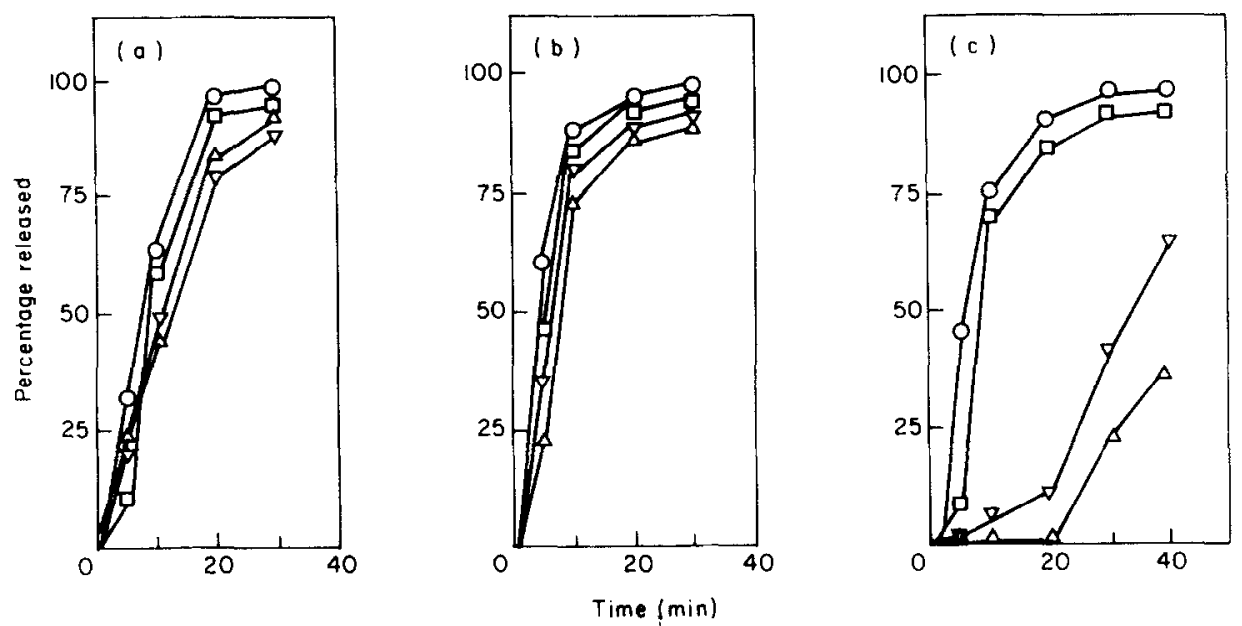

Fig. 2. Sensitivity of the cells on the various microcarriers to trypsin-mediated release. Microcarrier cultures were established on day zero as described in the Merhods section. Afrer two days in culture, 2-ml samples were taken from each culture and sensitiviry of the cells to trypsin-mediated release from the substrate determined. The values shown are averages of duplicate samples in a single experiment. Each cell type was examined three separate times with similar results: (a) MDBK, (b) chick embryo, (c) MRC-5. O, Glass: $\square$, collagen; $\triangle$, DEAE-dextran; $\nabla$, collagen-linked DEAE-dextran

\section{DISCUSSION}

Most primary cells, diploid cell strains and non-malignant cell lines have an absolute requirement for a substrate in order to proliferate in culture. The interaction of the cells with the substrate is thought to affect the arrangement of cellular structures involved in control of growth and other essential functions. It is not surprising in the light of this that cell behaviour may change dramatically when the substate on which the cells are grown is altered (see Roos ${ }^{9}$ for a review). In the study reported here we examined cell growth on four types of commercially-available microcarriers and compared cell yields from each substrate with the plating efficiency of the cells harvested from the same surface. The cells which were examined included primary cells (chick embryo) a diploid strain of human fibroblasts (MRC-5) and an established cell line (MDBK). Each of these cells is grown in industrial scale quantities for the production of vaccines used in human or animal medicinc. These studies were carried out because in the industrial scale production of anchorage-dependent cells (with batch sizes of 100-500 l or more), it is often necessary to subculture the cells one or more times in order to obtain a sufficient number of cells for use as the inoculum in the final culture. Additionally, with chick embryo cells, viable cells infected with a vaccine strain of Marek's disease virus constitute the vaccine. For these reasons the ability to harvest and re-utilize viable cells from the substrate may be as important as the ability of cells to proliferate on the substrate.

Substrate-dependent differences in both cell growth and recovery were observed in these studies. The established MDBK line grew to high densities on all of the substrates and the plating efficiency of the harvested cells from all of the substrates was high. In contrast, the MRC-5 cells grew well on all of the substrates but the plating efficiency of these cells was high only when harvested from the glass microcarriers or collagen microcarriers. The chick embryo cells, on the other hand, grew well only on the glass 
microcarriers. When the cells were harvested from this substrate their subsequent plating efficiency was high.

The sensitivity of the cells to trypsin-mediated release from the various substrates was also examined in these studies. This was done because it was known from previous reports ${ }^{5,6}$ that certain types of cells are very resistant to removal from DEAE-dextran beads but not from glass microcarriers. We wanted to determine, therefore, if there were a relationship between the ease with which the cells could be removed from a particular substrate and the subsequent plating efficiency of the released cells. The high plating efficiency of the MDBK cells harvested from all four substrates may reflect the fact that these cells could easily be harvested from the same microcarriers. Likewise, the low plating efficiency of the MRC- 5 cells harvested from the DEAE-dextran microcarriers may reflect the fact that these cells were very resistant to trypsin-mediated release from this substrate (Varani et al. ${ }^{5,6}$ and this report). However, this is not likely to be the explanation for the low plating efficiency of the chick cells. Unlike many other cells, the chick cells were easily harvested from the DEAE-dextran microcarriers with proteases. They were also easily removed from the collagen-linked DEAE-dextran and collagen microcarriers. It is more likely that the factors that contribute to poor cell growth on substances other than glass also contribute to the low plating efficiency of the harvested cells. Regardless of mechanism, these studies clearly indicated that there are significant differences between microcarrier substrates in their ability to produce cells which can be easily harvested and reutilized. The ease with which cells can be harvested from the glass microcarriers and the high plating efficiency of the cells harvested from this substrate suggest that the glass microcarriers may be particularly useful in the intermediate stages of large culture operations. The glass microcarriers may also be useful for tasks such as the production of Marek's disease virus vaccine, where viable, infected cells are needed.

\section{Acknowledgement}

This study was supported in part by grant R44 CA36656 from the USPHS.

\section{REFERENCES}

1. Van Wezel AL. Growth of cell strains and primary cells on microcarriers. Nature 1967; 216: 65-66

2. Gebb C, Clark JM, Hirtenstein MD, Lindgren G, Lindskog U, Lundgren B, Vretblad P. Alternative surfaces for microcarrier culture of animal cells. Dev Biol Stand 1982; 50: 93-102.

3. Kesse C, Giaever I. Cell growth on liquid microcarriers. Science 1983; 219: 1448-1449.

4. Nielsen V, Johansson A. Biosilon; optimal culture conditions and various research scale culture techniques. $1980 ; 46: 131-136$.

5. Varani J, Dame M, Bewals TF, Wass JA. Growth of three established cell lines on glass microcarriers. Biotech Bioengineer 1983; 25: 1359-1372.

6. Varani J, Dame M, Rediske J, Beals TF, Hillegas W. Substrate-dependent differences in growth and biological properties of fibroblasts and epithelial cells grown in microcarrier culture. J Biol Stand 1985; 13: 67-76.

7. Sanford K, Earle W, Evans V. The measurement of proliferation in tissue cultures by enumeration of cell nuclei. J Nat Cancer Inst 2950; 11: 773-794.

8. Varani J, Orr W, Ward PA. Adhesive characteristics of tumor cell variants of high and low tumorigenic potential. J Nat Cancer Inst 1980; 64: 668-672.

9. Roos E. Cellular adhesion, invasion and metastasis. Biochim Biophys Acta 1984; 738 : 263-284. 